\title{
Theoretical Evaluation of Ultrasonic Velocities in the Liquid Binary System of Isomeric Xylenes with Ethyl Lactate
}

\author{
K. A. K. RAJKUMAR ${ }^{1}$, G. R. SATYANARAYANA ${ }^{2}$, G. LAKSHMANA RAO ${ }^{1}$, \\ SHAIK BEEBI ${ }^{1}$, D. BALA ${ }^{1}$ and C. RAMBABU ${ }^{1 *}$ \\ ${ }^{1}$ Department of Chemistry, Acharya Nagarjuna University, Nagarjuna Nagar, \\ Guntur, Andhra Pradesh, India \\ ${ }^{2}$ Department of Chemistry, Sir.C.R.Reddy PG College, Eluru, Andhra Pradesh, India \\ rbchintala@gmail.com
}

Received 11 October 2016 / Accepted 6 November 2016

\begin{abstract}
Ultrasonic velocities and densities of the binary liquid mixtures of ethyl lactate with $o$-xylene, $m$-xylene and $p$-xylene have been measured, over the entire composition range of mole fractions at different temperatures from 303.15 to $318.15 \mathrm{~K}$ with an interval of $5 \mathrm{~K}$. The theoretical values of ultrasonic velocity were evaluated by using Nomoto (NOM), Impedance (IMP), Van Deal and Vangeel (VDV), Junjie's (JUN), Rao's specific velocity (RAO) models. The results are discussed in terms of non-ideality in the mixtures, molecular interaction parameter. Relative deviation $\sigma$ and Chi-square $\left(\chi^{2}\right)$ test for the goodness of the fit was applied to understand the applicability of these theories to the present systems.
\end{abstract}

Keywords: Ethyl lactate, Ultrasonic velocities, Chi-square test, Molecular interaction parameter

\section{Introduction}

The studies on ultrasonic velocities and their dependence on composition and temperature are of great importance in many fields of applied research and find applications in important chemical, industrial and biological processes. Ultrasonic velocities of liquid mixtures containing polar and non-polar groups are of considerable importance in understanding intermolecular interaction between component molecules ${ }^{1-6}$. Comparative studies on the experimental theoretical values of ultrasonic velocities for various organic liquid mixtures using different theories/ models like Nomoto ${ }^{7}$, Impedance relation ${ }^{8}$, Van Dael and Vangael ${ }^{9}$, Junjie $^{10}$ and Rao's specific velocity ${ }^{11}$ have been carried out by many researchers. The present study is a continuation of our research programme on application of theoretical models of ultrasonic velocities of liquid binaries at different temperatures ${ }^{12-16}$.

In this paper, we report the experimental and theoretical ultrasonic velocities of ethyl lactate (EL) with $o$-xylene, $m$-xylene and $p$-xylene evaluated by various theoretical models such as Nomoto (NOM), Impedance (IMP), Van Deal and Vangeel (VDV), Junjie (JUN), Rao's 
specific velocity (RAO) at 303.15-318.15 K over the entire composition range. Relative applicability of the theories to the present systems has been checked and discussed. Further, the results were explained in terms of molecular interaction parameter, deviation in the variation of $\mathrm{U}_{\text {exp }}^{2} / \mathrm{U}^{2}$ imx. Relative deviation $\sigma$ and Chi-square $\left(\chi^{2}\right)$ test for the goodness of the fit is applied to understand the applicability of these theories to the present systems.

\section{Experimental}

The pure solvents used in the present study such as ethyl lactate (EL) (Merk >99\%) and $o$-xylene (OXL), $m$-xylene (MXL) and $p$-xylene (PXL)) was acquired from S.D fine chemicals India ltd and were purified as described in the literature ${ }^{17,18}$. The density was measured with a pycnometer having a bulb volume of about $25 \mathrm{~cm}^{3}$ and an internal capillary diameter of about $1 \mathrm{~mm}$. The density was then determined from the mass of the sample and the volume of pycnometer. Uncertainties in density determinations were estimated to be within $\pm 0.0001 \mathrm{~g} \mathrm{~cm}^{-3}$. The ultrasonic velocity of sound (U) was measured using an ultrasonic interferometer (Mittal Enterprises, New Delhi model F05) operating at $2 \mathrm{MHz}$. The measured speeds of sound have a precision of $0.8 \mathrm{~m} \cdot \mathrm{s}^{-1}$ and an uncertainty less than $\pm 0.1 \mathrm{~m} \cdot \mathrm{sec}^{-1}$ and temperature stability was maintained within $\pm 0.01 \mathrm{~K}$ by circulating water bath around the measuring cell through a pump.

\section{Theoretical considerations}

\section{Nomoto theory}

Nomoto's empirical formula is based on the assumption of the linear dependence of the molecular sound velocity on concentration and the additivity of the molar volume in the liquid mixture. The sound velocity $\mathrm{U}$ is given by

$$
\mathrm{U}=\left[\frac{\sum_{i=1}^{n} x_{i} R_{i}}{\sum_{i=1}^{n} x_{i} V_{i}}\right]^{3}
$$

where the molar sound velocity $\mathrm{R}=\mathrm{x}_{1} \mathrm{R}_{1}+\mathrm{x}_{2} \mathrm{R}_{2}$. Hence, ultrasonic velocity $(\mathrm{U})$ is given by

$$
\mathrm{U}=\left[\frac{x_{1} R_{1}+x_{2} R_{2}}{x_{1} V_{1}+x_{2} V_{2}}\right]^{3}
$$

In the above equation $\mathrm{R}_{\mathrm{i}}=\left(\mathrm{M}_{\mathrm{i}} / \rho_{\mathrm{i}}\right) \mathrm{U}_{\mathrm{i}}^{1 / 3}=\mathrm{V}_{\mathrm{i}}\left(\mathrm{U}_{\mathrm{i}}\right)^{1 / 3}$

\section{Impedance relation}

The specific acoustic impedance of the pure liquids are used for evaluating the ultrasonic velocity in the liquid mixtures by the following relation:

$$
\mathrm{U}=\sum \mathrm{x}_{\mathrm{i}} \mathrm{Z}_{\mathrm{i}} / \sum \mathrm{x}_{\mathrm{ii}}
$$

where $Z_{i}$ is acoustic impedance and $\rho_{\mathrm{i}}$ is the density of the mixture.

\section{Van Dael and Vangeel relation}

Van Dael and Vangeel obtained the formula for ultrasonic velocity in the liquid mixtures adopting the adiabatic compressibilities of the pure liquids based on ideal mixing of the liquids. Van Dael and Vangeel assumed that the adiabatic compressibility $\left(\beta_{\mathrm{ad}}\right)$ of the mixture is given by

$$
\beta_{\mathrm{ad}}=\phi_{\mathrm{A}}\left(\beta_{\mathrm{ad}}\right)_{\mathrm{A}}+\phi_{\mathrm{B}}\left(\beta_{\mathrm{ad}}\right)_{\mathrm{B}}
$$

and suggested the following relation for sound velocity in homogeneous liquid mixtures. 


$$
\beta_{a d}^{i m}=\phi_{\mathrm{A}} \frac{\gamma_{\mathrm{A}}}{\gamma^{j m}}\left(\beta_{a d}\right)_{A}+\phi_{\mathrm{B}} \frac{\gamma_{\mathrm{B}}}{\gamma^{j m}}\left(\beta_{a d}\right)_{B}
$$

Where $\phi$ and $\gamma$ refer the volume function and principal specific ratio. It holds true if the mixture is an ideal one and also $\gamma_{\mathrm{A}}=\gamma_{\mathrm{B}}=\gamma_{\mathrm{im}}$. It can be transformed into a linear combination of the mole fractions if the additional assumption $\mathrm{v}_{\mathrm{A}}=\mathrm{v}_{\mathrm{B}}$ is made

$$
\beta_{\mathrm{ad}}^{\mathrm{im}}=\mathrm{x}_{\mathrm{A}}\left(\beta_{\mathrm{ad}}\right)_{\mathrm{A}}+\mathrm{x}_{\mathrm{B}}\left(\beta_{\mathrm{ad}}\right)_{\mathrm{B}}
$$

The sound velocities appropriate to the above equations are given by

$$
\begin{aligned}
& \frac{x_{A} v_{A}+x_{B} v_{B}}{x_{A} M_{A}+x_{B} M_{B}} \frac{1}{\left(U^{i m}\right)^{2}}=\varphi_{A} \frac{v_{A}}{M_{A} U_{A}^{2}}+\varphi_{B} \frac{v_{B}}{M_{B} U_{B}^{2}} \\
& \frac{1}{x_{A} M_{A}+x_{B} M_{B}} \frac{1}{\left(U^{i m}\right)^{2}}=\frac{x_{A}}{M_{A} U_{A}^{2}}+\frac{x_{B}}{M_{B} U_{B}^{2}}
\end{aligned}
$$

\section{Junjie's relation}

This relation derived by Junjie for the ultrasonic velocity of the mixture in terms of the mole fraction, molecular weight and density of the mixture is given as

$$
U=\frac{\sum_{i=1}^{n} x_{i} V_{i}}{\left(\sum_{i=1}^{n} x_{i} M_{i}\right)^{1 / 2}\left(\sum_{i=1}^{n} x_{i} V_{i} / \rho_{i} u_{i}^{2}\right)^{1 / 2}}
$$

where the symbols have their usual meanings.

\section{Rao's relation}

Using the ratio of the temperature coefficient of velocity and expansion coefficient, Rao derived a formula for ultrasonic velocity $(\mathrm{U})$

$$
\mathrm{U}=\left(\frac{R}{V}\right)^{3}
$$

Where $\mathrm{V}$ is the molar volume and $\mathrm{R}$ is called Rao's constant or molar sound velocity, which is constant for a liquid at a temperature.

\section{Chi-square test for goodness of fit}

According to Karl Pearson, Chi-square value is evaluated for the binary liquid mixtures under study using the formula

$$
x^{2}=\sum_{i=1}^{n}\left(\left(U_{(o b s)}-U_{(c a l)} 2 / U_{(c a l)}\right.\right.
$$

where $\mathrm{n}$ is the number of data used and ' $\mathrm{U}_{\text {(obs) }}=$ experimental values of ultrasonic velocities, $\mathrm{U}_{\text {(cal) }}=$ computed values of ultrasonic velocities

Relative percentage of error $(\sigma)$

The Average percentage error is calculated by using the relation 


$$
\sigma=1 / \mathrm{n} \sum\left(\left(\mathrm{U}_{(\mathrm{obs})}-\mathrm{U}_{(\mathrm{cal})}\right) / \mathrm{U}_{(\mathrm{obs})}\right) \mathrm{X} 100 \%
$$

Where $\mathrm{n}$ is the number of data used. $\mathrm{U}_{(\mathrm{obs})}=$ experimental values of ultrasonic velocities.

\section{Molecular associations}

The degree of intermolecular interaction or molecular association is given by

$$
\boldsymbol{\alpha}=\left[\mathrm{U}^{2}{ }_{\text {exp }} / \mathrm{U}^{2}{ }_{\text {imx }}\right]-1
$$

\section{Results and Discussion}

The experimental ultrasonic velocities and the theoretical values evaluated by Nomoto's Relation (NOM), Impedance Relation (IMP), Van Deal and Vangeel Ideal Mixing Relation (VDV), Junjie's relation (JUN), Rao's specific velocity method (RAO) are compared for all the three binaries $\mathrm{EL}+o$-xylene, $\mathrm{EL}+m$-xylene, $\mathrm{EL}+p$-xylene along with the percentage of deviations are presented in Tables 1-3 at all the four temperatures 303.15, 308.15, 313.15, $318.15 \mathrm{~K}$ and atmospheric pressure. The validity of different theoretical formulae is checked by the chi-square test for all the mixtures at all the temperatures and the values are given in Table 4 .

Table 1. Experimental and theoretical values of velocities with their \% deviations for the

\begin{tabular}{|c|c|c|c|c|c|c|c|c|c|c|c|c|}
\hline \multicolumn{13}{|c|}{ AT $303.15 \mathrm{~K}$} \\
\hline $\mathrm{X}_{1}$ & EXP & NOM & IMP & VDV & JUN & RAO & $\% \mathrm{NO}$ & IVIII & $\% \mathrm{VD}$ & $\% \mathrm{JU}$ & $\mathrm{RAO}$ & $\alpha$ \\
\hline 0000 & 1337.8 & 1337.8 & 1337.8 & 1337.8 & 1337.8 & 1337.8 & 0.00 & 0.00 & 0.00 & 0.00 & 0.00 & 0000 \\
\hline & & & & & & & & & & & & \\
\hline & & & & & & & & & & & 38 & \\
\hline & & & & & & & & & & & & \\
\hline & & & & & & & & & & & & \\
\hline & & & & & & & & & & & & \\
\hline & & & & & & & & & & & & \\
\hline & & & & & & 3 & & & & & 2.51 & \\
\hline & & & & & & & -0 & & & & 1.75 & \\
\hline & & & & & & & & & & & & \\
\hline & & & & & $\ldots$ & & & & & & & \\
\hline \multicolumn{13}{|c|}{$3.15 \mathrm{~K}$} \\
\hline $\mathrm{X}_{1}$ & EXP & & & & & $\mathrm{O}$ & & 1 & & & & u \\
\hline & & & & & & & & & & & & \\
\hline & & & & & & & & & & & & \\
\hline & & & & & & & & & & & 1.96 & \\
\hline & & & & & & & & & & & 54 & \\
\hline & & & & & & & & & & & & \\
\hline & & & & & & & & & & & & \\
\hline & & & & & & & & & & & & \\
\hline & & & & & & & & & & & & \\
\hline & & & & & & & & & & & 1. & \\
\hline & & & & & & & -0 & & & & 0. & 023 \\
\hline & & & & & 2.6 & 1242.6 & 0. & 0. & 0. & 0.00 & 0.00 & 0.000 \\
\hline \multicolumn{13}{|c|}{ I $313.15 \mathrm{~K}$} \\
\hline & $P$ & $\mathrm{NOI}$ & IMP & & $\mathrm{N}$ & $\mathrm{AO}$ & $\% \mathrm{NC}$ & $\%$ & & & $\mathrm{FR}$ & \\
\hline & & & 5 & & & & & & & & 0.00 & 0 \\
\hline & & & & & & & & & & & & \\
\hline & 01.0 & .2 & 1211.0 & & 1211.0 & 1307.4 & 0. & -0.31 & -0.24 & -0.25 & 2.06 & 0.004 \\
\hline
\end{tabular}
system $(\mathrm{EL}+\mathrm{OXL})$ 


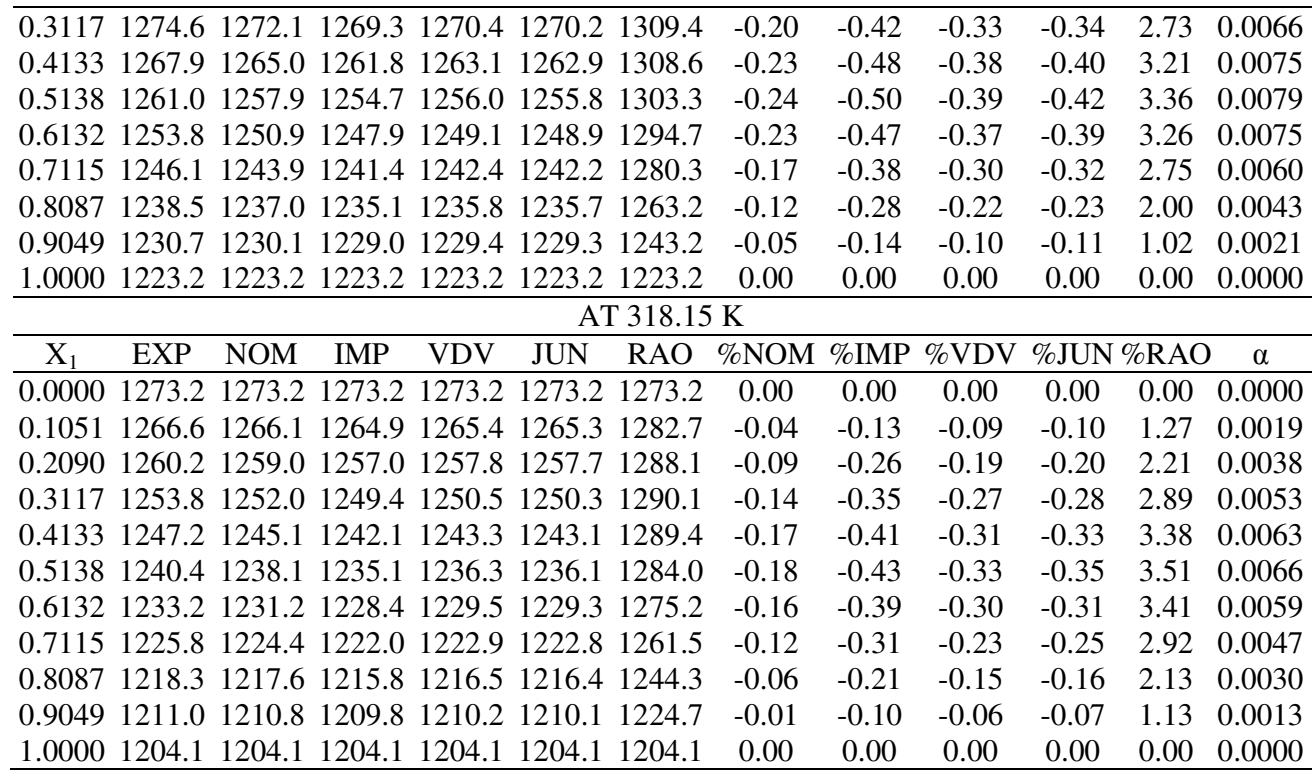

Table 2. Experimental and theoretical values of velocities with their \% deviations for the system (EL+MXL)

\begin{tabular}{|c|c|c|c|c|c|c|c|c|c|c|c|c|}
\hline \multicolumn{13}{|c|}{ AT $303.15 \mathrm{~K}$} \\
\hline $\mathrm{X}_{1}$ & EXP & NOM & IMP & VDV & JUN & RAO & $\% \mathrm{NOM}$ & $\%$ IMP & $\% \mathrm{VDV}$ & $\% \mathrm{JUN}$ & $\%$ RAO & $\alpha$ \\
\hline 0.0000 & 1304.0 & 1304.0 & 1304.0 & 1304.0 & 1304.0 & 1304.0 & 0.00 & 0.00 & 0.00 & 0.00 & 0.00 & 0.0000 \\
\hline 0.1035 & 1301.7 & 1299.8 & 1298.8 & 1299.1 & 1298.5 & 1316.0 & -0.15 & -0.22 & -0.20 & -0.25 & 1.10 & 0.0040 \\
\hline .2062 & 1298.9 & 1295.6 & .9 & 1294.4 & 3.3 & 1327.8 & -0.26 & -0.39 & -0.35 & -0.43 & 2.23 & 0.0070 \\
\hline 1 & 12 & 1 & 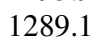 & 7 & 1 & 13 & -0. & -0 & -0.44 & -0 . & 3.03 & 0.0089 \\
\hline 0.4092 & 1291.6 & 12 & 1284.6 & 1285.3 & 1283.6 & 1337.4 & -0.35 & -0.54 & -0.49 & -0.62 & 3.54 & 0.0098 \\
\hline 0.5095 & 1287.4 & 1282.8 & 1280.3 & 1281.0 & 1279.2 & 1337.1 & -0.36 & -0.55 & -0.50 & -0.63 & 3.86 & 0.0101 \\
\hline 0.6091 & 1282.9 & 1278.5 & 1276.1 & 1276.8 & 1275.1 & 1331.8 & -0.34 & -0.53 & -0.48 & -0.61 & 3.82 & 0.0096 \\
\hline 0.7080 & 1278.2 & 1274.2 & 1272.2 & 1272.7 & 1271.2 & 1320.0 & -0.31 & -0.47 & -0.43 & -0.55 & 3.27 & 0.0087 \\
\hline & 1272.9 & 126 & 126 & 126 & 17 & 13 & -0.24 & -0.36 & -0.33 & -0.42 & 2.26 & 0.0066 \\
\hline & 126 & & 1264.7 & 126 & & & -0.13 & -0.20 & -0.18 & -0.23 & 1.13 & 0.0036 \\
\hline 1.0000 & 1261.2 & 1261.2 & 1261.2 & 1261.2 & 1261.2 & 1261.2 & 0.00 & 0.00 & 0.00 & 0.00 & 0.00 & 0.0000 \\
\hline
\end{tabular}
$\begin{array}{rrrr}1.00001261 .2 & 1261.21261 .2 & 1261.21261 .2 & 1261.2 \quad 0.00 \\ \text { AT } 308.15 \mathrm{~K}\end{array}$

\begin{tabular}{ccccccccccccc}
\hline $\mathrm{X}_{1}$ & EXP & NOM & IMP & VDV & JUN & RAO & \%NOM & \%IMP & \%VDV & \%JUN & \%RAO & $\alpha$ \\
\hline 0.0000 & 1285.5 & 1285.5 & 1285.5 & 1285.5 & 1285.5 & 1285.5 & 0.00 & 0.00 & 0.00 & 0.00 & 0.00 & 0.0000 \\
0.1035 & 1282.8 & 1281.3 & 1280.3 & 1280.6 & 1280.0 & 1299.0 & -0.12 & -0.20 & -0.17 & -0.22 & 1.26 & 0.0034 \\
0.2062 & 1279.7 & 1277.1 & 1275.3 & 1275.8 & 1274.7 & 1311.4 & -0.20 & -0.34 & -0.30 & -0.39 & 2.48 & 0.0061 \\
0.3081 & 1276.2 & 1272.9 & 1270.6 & 1271.2 & 1269.7 & 1318.1 & -0.26 & -0.44 & -0.39 & -0.51 & 3.28 & 0.0078 \\
0.4092 & 1272.4 & 1268.6 & 1266.0 & 1266.8 & 1265.0 & 1321.0 & -0.30 & -0.50 & -0.44 & -0.58 & 3.82 & 0.0089 \\
0.5095 & 1268.2 & 1264.3 & 1261.7 & 1262.4 & 1260.6 & 1319.9 & -0.31 & -0.51 & -0.45 & -0.60 & 4.07 & 0.0092 \\
0.6091 & 1263.7 & 1260.0 & 1257.5 & 1258.2 & 1256.5 & 1314.3 & -0.29 & -0.49 & -0.43 & -0.57 & 4.01 & 0.0087 \\
0.7080 & 1258.9 & 1255.7 & 1253.6 & 1254.1 & 1252.6 & 1302.5 & -0.25 & -0.42 & -0.38 & -0.50 & 3.46 & 0.0076 \\
0.8060 & 1253.7 & 1251.3 & 1249.7 & 1250.2 & 1249.0 & 1284.5 & -0.19 & -0.32 & -0.28 & -0.38 & 2.46 & 0.0057 \\
0.9034 & 1248.4 & 1247.0 & 1246.1 & 1246.3 & 1245.6 & 1263.7 & -0.11 & -0.18 & -0.17 & -0.22 & 1.23 & 0.0033 \\
1.0000 & 1242.6 & 1242.6 & 1242.6 & 1242.6 & 1242.6 & 1242.6 & 0.00 & 0.00 & 0.00 & 0.00 & 0.00 & 0.0000 \\
\hline
\end{tabular}
AT $313.15 \mathrm{~K}$

\begin{tabular}{ccccccccccccc}
\hline $\mathrm{X}_{1}$ & EXP & NOM & IMP & VDV & JUN & RAO & \%NOM & \%MP & \%VDV & \%JUN & \%RAO & $\alpha$ \\
\hline 0.0000 & 1265.8 & 1265.8 & 1265.8 & 1265.8 & 1265.8 & 1265.8 & 0.00 & 0.00 & 0.00 & 0.00 & 0.00 & 0.0000
\end{tabular}




\begin{tabular}{|c|c|c|c|c|c|c|c|c|c|c|c|}
\hline 035 & .9 & & & & .9 & .10 & .18 & 0.16 & -0.21 & 1.43 & 1 \\
\hline 0.2062 & 59.5 & 57.5 & .7 & 56.2 & 55.01293 .0 & -0.16 & -0.31 & -0.26 & -0.35 & 2.66 & 052 \\
\hline 0.30 & 6.0 & 3.3 & 0.9 & 1.7 & 0.5 & -0.22 & -0.40 & -0.35 & -0.47 & 3.54 & 10 \\
\hline 0.4092 & & 19.0 & 6.4 & 47.2 & 3.2 & -0.25 & 46 & 0.40 & -0.54 & 4.07 & \\
\hline 0. & .9 & 244 & .1 & 42.9 & 1241.0 & -0.25 & -0.46 & -0.40 & -0.55 & 4.31 & 80 \\
\hline $0 . c^{2}$ & 43.5 & 40.5 & 38.0 & 50 & 1236.9 & -0.24 & 44 & 38 & .53 & 4.22 & 11 \\
\hline 0 & 38.8 & 56.2 & 34.1 & 1234.7 & 1233.1 & -0.21 & 38 & 33 & 46 & 3.70 & 0067 \\
\hline 0.8060 & 1233.8 & 251. & 30.3 & 230.7 & $1229.5 \quad 1266.8$ & -0.15 & -0.28 & -0.25 & -0.35 & 2.67 & 0.0050 \\
\hline & 228.6 & 227.6 & 26.7 & 226.9 & 1226.21 & -0.08 & -0.16 & -0.14 & -0.19 & 1.35 & 0.0027 \\
\hline & & & & & 1223.2 & 0.00 & 0.00 & 0.00 & 0.00 & 0.00 & 0000 \\
\hline \multicolumn{12}{|c|}{ AT $318.15 \mathrm{~K}$} \\
\hline$X_{1}$ & EXP & NOM & IMP & VDV & JUN & $\% \mathrm{NOM}$ & \%IMP & $\% \mathrm{VDV}$ & $\% \mathrm{JUN}$ & $\% \mathrm{RAO}$ & $\alpha$ \\
\hline 000 & 1244.4 & 4 & 44.4 & 244.4 & 1244.41244 .4 & 0.00 & 0.00 & 0.00 & 0.00 & 0.00 & 0.0000 \\
\hline & 41.3 & & 39.5 & 1239.8 & 1239.2126 & -0.07 & 14 & -0.12 & -0.17 & 52 & 024 \\
\hline 62 & 1237.9 & 1236.5 & 1234.8 & 1235.3 & $\begin{array}{lll}1234.2 & 1272.8\end{array}$ & -0.11 & -0.25 & -0.21 & -0.30 & 2.82 & 042 \\
\hline 3081 & 234.5 & 1232.5 & 230.4 & 1231.0 & 1229.61279 .7 & -0.16 & -0.33 & -0.29 & -0.40 & 3.66 & 0.0057 \\
\hline 4092 & 1230.8 & 1228.5 & 1226.1 & 1226.8 & 1225.11282 .5 & -0.19 & -0.38 & -0.33 & -0.46 & 4.20 & 0.0066 \\
\hline 0.5095 & 226.8 & 1224.5 & 1222.1 & 1222.7 & $\begin{array}{lll}1221.0 & 1280.9\end{array}$ & -0.19 & -0.39 & -0.33 & -0.47 & 4.41 & 0.0067 \\
\hline 091 & 22.8 & 1220.4 & 1218.2 & 1218.8 & 1217.11275 .5 & -0.19 & -0.38 & -0.33 & -0.47 & 4.31 & 0.0067 \\
\hline & 4 & & & 1214.9 & $1213.5 \quad 1264.7$ & -0.17 & -0.33 & -0.29 & -0.40 & 3.80 & 0057 \\
\hline 60 & 213.7 & 1212.3 & 1210.8 & 1211.2 & 1210.11246 .6 & -0.11 & -0.23 & -0.21 & -0.30 & 2.71 & 0.0041 \\
\hline & .8 & 3.2 & 97.4. & 07.6 & $1207.0 \quad 1226.4$ & -0.05 & -0.12 & -0.10 & -0.15 & 1.45 & 0.0020 \\
\hline 1.0000 & 1204.1 & 1204.1 & 1204.1 & 1204.1 & $1204.1 \quad 1204.1$ & 0.00 & 0.00 & 0.00 & 0.00 & 0.00 & 0.0000 \\
\hline
\end{tabular}

Table 3. Experimental and theoretical values of velocities with their \% deviations for the system (EL+PXL)

\begin{tabular}{|c|c|c|c|c|c|c|c|c|c|c|c|c|}
\hline \multicolumn{13}{|c|}{ AT $303.15 \mathrm{~K}$} \\
\hline$X_{1}$ & EXP & NOM & IMP & VDV & JUN & KAU & $\% \mathrm{NOM}$ & $\%$ IMP & $\% \mathrm{VDV}$ & $\% \mathrm{JUN}$ & $\% \mathrm{RAO}$ & $\alpha$ \\
\hline .0000 & 1286.8 & 1286.8 & 1286.8 & 1286.8 & 1286.8 & 1286.8 & 0.00 & 0.00 & 0.00 & 0.00 & 0.00 & $\overline{000}$ \\
\hline & & & & & & & & -( & .22 & -0.29 & & \\
\hline & & & & & & & & & & & & \\
\hline & & & & & & & & & & -( & & \\
\hline & & & & & & & -0.46 & -0. & -0.59 & -0.78 & 4.35 & 120 \\
\hline & & & & & .7 & & -0. & -0. & -0. & -0.81 & .93 & 125 \\
\hline & & & & & & & & & & & & \\
\hline & & & & & & & & & & & & \\
\hline & & & & & & & & & & & & \\
\hline & & & & & & & -0 & -0 & & -0 & & \\
\hline & & & & & 1.2 & & 0. & & & & 0.0 & 0000 \\
\hline \multicolumn{13}{|c|}{ AT $308.15 \mathrm{~K}$} \\
\hline $\mathrm{X}_{1}$ & EXP & NOM & IMP & VDV & JUN & RAO & $\%$ NOM & $\%$ IMP & $\% \mathrm{VDV}$ & $\% \mathrm{JUN}$ & $\%$ RAO & $u$ \\
\hline 0000 & 274.7 & 274.7 & 1274.7 & 1274.7 & 1274.7 & & & & & & 0 & 100 \\
\hline & & & & & & & & & & -0 . & & 4 \\
\hline & & & & & & & & & & & & \\
\hline & & & & & & & & & & & & \\
\hline & & & & & & & & & & & & \\
\hline & & & & & & & & & & -0 & & \\
\hline & & 3 & & & & & & & & -0 & & \\
\hline & 12 & & & & & & & & & -0 & .49 & 102 \\
\hline & & & & & & & & & & -0.49 & & \\
\hline & & & & & & & -0 & & & & & 0.003 \\
\hline 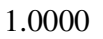 & 1 & $12-2.0$ & $12+2.0$ & $12-72.0$ & 2.0 & 2.0 & $0 .($ & 0.00 & 0.00 & 0.00 & 0.00 & 0.0000 \\
\hline
\end{tabular}




\begin{tabular}{|c|c|c|c|c|c|c|c|c|c|c|c|c|}
\hline \multicolumn{13}{|c|}{ AT $313.15 \mathrm{~K}$} \\
\hline $\mathrm{X}_{1}$ & EXP & NOM & IMP & VDV & JUN & $\mathrm{RAO}$ & $\% \mathrm{NOM}$ & \%IMP & $\%$ VDV & $\% \mathrm{JUN}$ & \%RAO & $\alpha$ \\
\hline 0.0000 & 1251.1 & 1251.1 & 1251.1 & 1251.1 & 1251.1 & 1251.1 & 0.00 & 0.00 & 0.00 & 0.00 & 0.00 & 0.0000 \\
\hline 0.1070 & 1249.8 & 1248.3 & & 1247.6 & 1246.8 & 1265.8 & -0.12 & -0.18 & -0.17 & -0.24 & 1.28 & .0035 \\
\hline 0.2124 & 4 & 5 & 3 & 1244.3 & 1242.9 & 1281.6 & -0.23 & -0.33 & -0.33 & -0.44 & 2.66 & 0.0066 \\
\hline 0.3 & & 1242.7 & & 12 & & 1292.6 & -0.31 & -0.43 & -0.43 & -0.57 & 3.70 & 0.0 \\
\hline 0.4184 & & 1239.9 & & & & 1300.5 & -0.36 & -0.50 & -0.50 & -0.66 & 4.51 & 0.01 \\
\hline 0.5190 & 1241.9 & 1237.1 & 1235.4 & 1235.4 & 1233.2 & 1304.7 & -0.39 & -0.52 & -0.53 & -0.70 & 5.06 & 0.0106 \\
\hline 0.6181 & 1239.1 & 1234.3 & 1232.7 & 1232.7 & 1230.6 & 1301.2 & -0.39 & -0.52 & -0.52 & -0.69 & 5.01 & 0.0104 \\
\hline 0.7 & & & & & & 1292.2 & -0.35 & -0.46 & -0.46 & -0.61 & 4.56 & 0.0092 \\
\hline 0. & & & & & 3 & 12 & -0.2 & -0 & -0.33 & -0.45 & 3.74 & 0.0067 \\
\hline 0 . & 1227.5 & 0 & 12 & 12 & 6 & 12 & -0.1 & -0 & -0.17 & -0.24 & 2.33 & 0.0034 \\
\hline 00 & 1223.2 & 1223.2 & 1223.2 & 1223.2 & 1223.2 & 1223.2 & 0.00 & 0.00 & 0.00 & 0.00 & 0.00 & 0.0000 \\
\hline \multicolumn{13}{|c|}{ AT $318.15 \mathrm{~K}$} \\
\hline$\overline{X_{1}}$ & EXP & NOM & IMP & VDV & JUN & RAO & $\% \mathrm{NOM}$ & \%IMP & \%VDV & $\% \mathrm{JUN}$ & $\%$ RAO & $\alpha$ \\
\hline 0.0000 & 1233.6 & 1233.6 & 1233.6 & 1233.6 & 1233.6 & 1233.6 & 0.00 & 0.00 & 0.00 & 0.00 & 0.00 & 0.0000 \\
\hline 0.1070 & 1232.0 & 1230.6 & 1229.9 & 1230.0 & 1229.2 & 1248.6 & -0.11 & -0.17 & -0.17 & -0.23 & 1.35 & 0.0033 \\
\hline 0 & 2 & 12 & & 6.5 & & 126 & -0 & -0.31 & -0.30 & -0.41 & 2.71 & 0.0060 \\
\hline & & & & & & & -0 & -0 & -0.40 & -0.54 & 3.81 & 0.0080 \\
\hline & & & & 12 & 12 & 12 & -0 & & -0.48 & -0.64 & 4.67 & 0.0 \\
\hline & 1223.1 & $121 \xi$ & 12 & 12 & 1215.0 & 1286.2 & -0.35 & -0.50 & -0.49 & -0.66 & 5.16 & 0.0099 \\
\hline 0.6181 & 1220.0 & 1215.8 & 1214.1 & 1214.2 & 1212.2 & 1282.5 & -0.34 & -0.48 & -0.47 & -0.64 & 5.13 & 0.0095 \\
\hline 7157 & 1216.6 & 1212.9 & 1211.5 & 1211.5 & 1209.8 & 1273.9 & -0.31 & -0.42 & -0.42 & -0.56 & 4.71 & 0.0084 \\
\hline & & 1209.9 & 1208.9 & 1208.9 & 1207.6 & 1258.8 & -0.21 & -0.30 & -0.30 & -0.41 & 3.82 & 0.0059 \\
\hline & 2 & 1207.0 & & & 120 & $12 ?$ & -0.10 & -0 . & -0.14 & -0.21 & 2.47 & 0.0029 \\
\hline 1.0000 & & 4.1 & 1204.1 & 1204.1 & 1204.1 & 1204.1 & 0.00 & 0.00 & 0.00 & 0.00 & 0.00 & 0.0000 \\
\hline
\end{tabular}

Table 4. Values of $\chi^{2}$ and $\boldsymbol{\sigma}$ for all values of the 3 binary mixturesat 4 different temperatures system-I (EL+OXL)

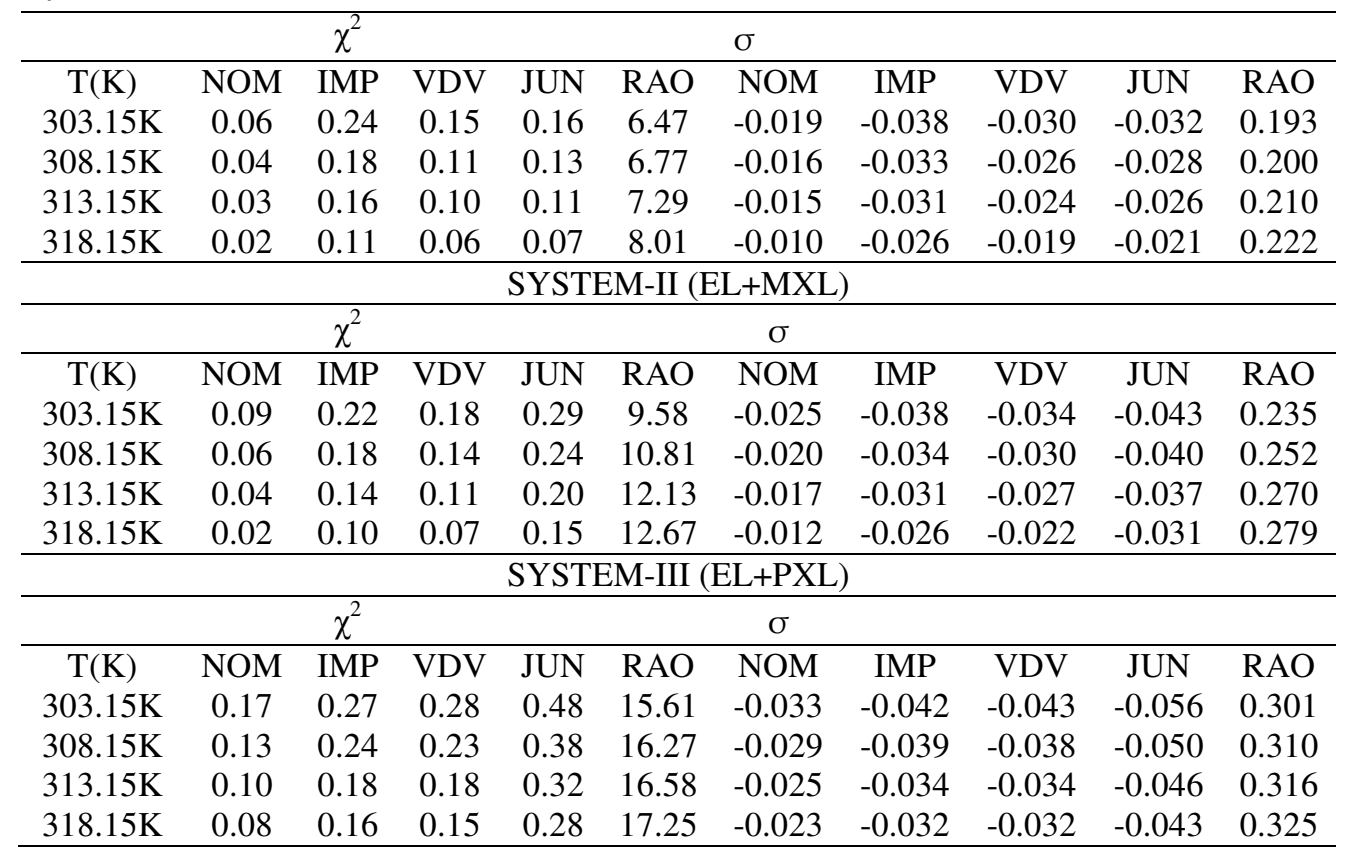


The data reveals that the velocities computed from Nomoto's relation (NOM), Impedance relation (IMP), Van Deal and Vangeel Ideal Mixing Relation (VDV) and Junjie's relation (JUN) exhibit more satisfactory agreement with the experimental values in the temperature range $303.15 \mathrm{~K}$ to $318.15 \mathrm{~K}$ than the Rao's specific velocity method (RAO). It is observed that the experimental values show deviation with the theoretical values of ultrasonic velocities which confirms the existence of molecular interactions ${ }^{19}$. This may be due to interactions occurring between the hetero molecules of the binaries. Higher deviations are observed in Rao's specific velocity method. There are higher variations in some intermediate concentration range suggesting the existence of strong tendency of association between component molecules as a result of dipole-dipole interactions. However, there is reasonably a good agreement between the experimental and theoretical velocities of Nomoto's relation and Impedance relation. Nomoto's theory proposes that the volume does not change upon mixing. Therefore, no interaction between the components of liquid mixtures has been taken into account. Similarly, the assumption for the formation of ideal mixing relation is that, the ratios of specific heats of ideal mixtures and the volumes are also equal. Again no molecular interactions are taken into account. But upon mixing, interactions between the molecules occur because of the presence of various types of forces such as dispersion forces, charge transfer, hydrogen bonding dipole-dipole and dipole-induced dipole interactions. Thus, the observed deviation of theoretical values of velocity from the experimental values shows that the molecular interactions are taking place between the unlike molecules in the liquid mixtures. From the Tables it is observed that maximum positive deviation is observed approximately at 0.5 mole fraction for all the three systems at all the temperatures. The ratio $\mathrm{U}_{\text {exp }}^{2} / \mathrm{U}^{2}{ }_{\text {imx }}$ is an important tool to measure the non ideality in the mixtures especially in such cases where the properties other than sound velocity are not known.

Figures 1-3 represent the variation of $\mathrm{U}_{\text {exp }}^{2} / \mathrm{U}^{2}$ imx with the mole fraction of EL for all three binary systems studied, and the ratio of $\mathrm{U}_{\text {exp }}^{2} / \mathrm{U}^{2}$ imx gives an idea of extent of interaction taking place between molecules of the mixtures. The positive deviation for the systems infers strong interactions between the components. The percentage of deviation in velocity is reflecting both negative and positive magnitudes, indicating non ideal behaviour of liquid mixtures. The evaluated interaction parameters are positive for all the systems, indicating strong interactions between the mixing molecules. The negative values of interaction parameter indicate the dominance of dispersion forces. But a positive value of $(\alpha)$ in all the system clearly indicates the existence of strong tendency for the formation of association in mixture through strong dipoledipole / dipole-induced dipole interactions and values of percentage deviation indicates the departure of the particular theory from experiment at that particular concentration and magnitude of the chi-square value finally determines the overall validity of the theory. The chisquare values along with average percentage error sigma are given in Table 4.

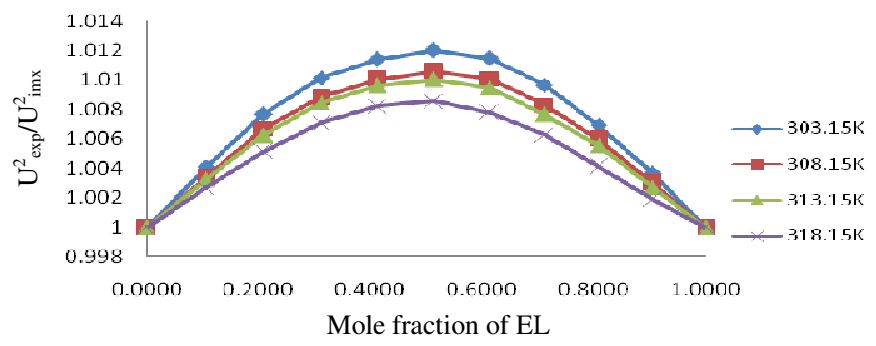

Figure 1. Plots of $\mathrm{U}_{\text {exp }}^{2} / \mathrm{U}^{2}{ }_{\text {imx }} v s . \mathrm{X}_{1}$ for the studied system EL+OXL, at temperatures $303.15,308.15,313.15$ and $318.15 \mathrm{~K}$ 


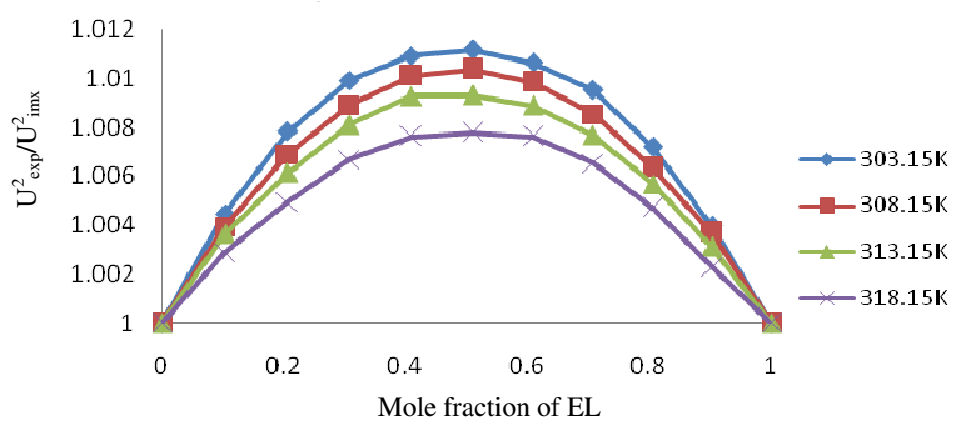

Figure 2. Plots of $\mathrm{U}^{2}$ exp $/ \mathrm{U}^{2}$ imx $v$ s. $\mathrm{X}_{1}$ for the studied system EL+MXL, at temperatures $303.15,308.15,313.15$ and $318.15 \mathrm{~K}$

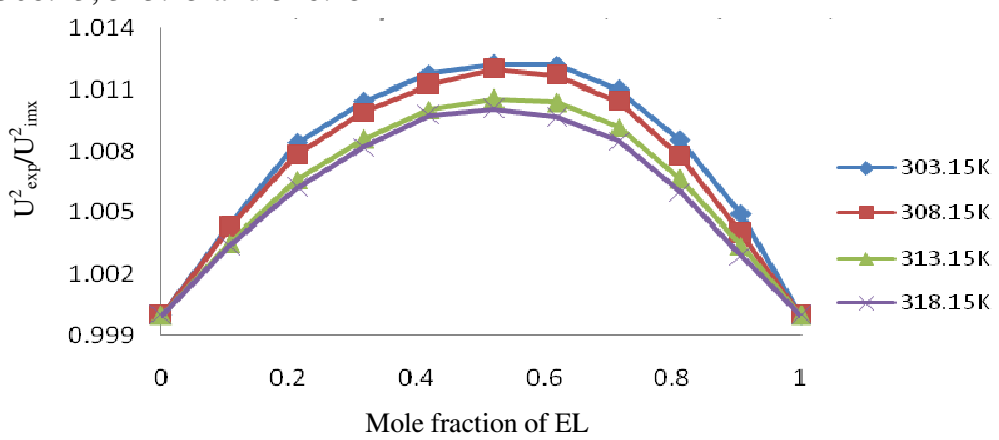

Figure 3. Plots of $\mathrm{U}_{\text {exp }}^{2} / \mathrm{U}^{2}{ }_{\text {imx }} v s . \mathrm{X}_{1}$ for the studied system EL+PXL, at temperatures $303.15,308.15,313.15$ and $318.15 \mathrm{~K}$

\section{Conclusion}

From the values of experimental and evaluated velocity values, it may be concluded that, the Nomoto's relation, Impedance relation, Van Deal and Vangeel Ideal Mixing Relation, Junjie's relation have provided good agreement. Thus, the linearity of molar sound velocity and additivity of molar volumes, as suggested by these models in deriving the empirical relations have been truly observed in the aforementioned binary liquid mixtures. The success of Nomoto's relation in predicting the experimental ultrasonic velocities for polar-polar liquid mixtures has also been emphasized by others ${ }^{15}$.

\section{References}

1. Satyanarayana G R, Kumar D B K, Sujatha K, Lakshmanarao G and Rambabu C, $J$ Molec Liq., 2016, 216, 526-537; DOI:10.1016/j.molliq.2016.01.054

2. Malik N I, Iajardar S P and Oswal S B, Thermochimica Acta, 2012, 539, 71-83; DOI:10.1016/j.tca.2012.04.002

3. Rayapa Reddy K, Kumar D B K, Srinivasa Rao G, Anila P and Rambabu C, Thermochimica Acta, 2014, 590, 116-126; DOI:10.1016/j.tca.2014.06.026

4. Kumar D B K, Rayapa ReddyK, Srinivasa Rao G, Rama Rao G V and Rambabu C, $J$ Molec Liq., 2012, 174, 100-111; DOI:10.1016/j.molliq.2012.07.019

5. Kumar D B K, Rayapa ReddyK, Srinivasa Rao G, Rama Rao G V, Sandya Sri P B, Sairam P V S and Rambabu C, J Mole Liq., 2014, 199, 352-363; DOI:10.1016/j.molliq.2014.09.024 
6. Anila P, Rayapa Reddy K, Srinivasa Rao G, Sairam P B S, Ramachandran D and Rambabu C, Thermochimica Acta, 2016, 620, 1-9; DOI:10.1016/j.tca.2015.09.021

7. Nomoto O, J Phys Soc Japan, 1958, 13(12), 1528-1532; DOI: 10.1143/JPSJ.13.1528

8. Baluja S and Parsania P H, Asian J Chem., 1955, 7(2), 417-423.

9. Van Dael W and Vangeel E, Pro Int Conf on Calorim Therm., Warsaw, 1955, 555.

10. Junjie Z, J China Univ Sci Technol, 1984, 14, 298.

11. Rama Rao M, J Chem Phys., 1941, 9(9), 682; DOI:10.1063/1.1750976

12. Ramarao G V, Krishna J S R and Rambabu C, Indian J Pure Appl Phys., 2005, 43, 345.

13. Lakshmana Rao G, Sandhya Sri P B, Satyanarayana G R and Rambabu C, Der Pharma Chemica, 2015, 7(10), 398-408.

14. Satyanarayana G R, Sujatha K, Zareena Begum and Rambabu C, Phys Chem An Indian J., 2014, 9(8), 283-291.

15 Satyanarayana G R, Krishna K B M, Sujatha K and Rambabu C, Der Pharma Chemica, 2014, 6(5),158-165.

16. Lakshmi B J, Sankar M G, Begum Z, Ramachandran D and Rambabu C, Elixir Ultrasonics, 2013, 65, 19808-19814.

17. Bunger WB, Reddick J A, \& Sankano T K, Organic Solvents, 3,4 Edn., Weissberger A, Wiley Interscience, New York, 1986.

18. Weissberger, Proskaner E S, Riddick and Toops E E, Organic Solvents, 2, $2^{\text {nd }}$ Edn., Weissberger A, Wiley Interscience, New York, 1955.

19. Satyanarayana G R, Sandya Sri P B, Sujatha K and Rambabu C, Elixir Appl Chem., 2014, 77, 29018-29023. 